\title{
16
}

\section{Assessing the Potential For Rehabilitation of Surface Permeability Using Regenerative Air and Vacuum Sweeping Trucks}

\author{
Jennifer A. P. Drake and Andrea Bradford
}

Permeable pavements (PPs) have been used as stormwater management systems throughout Ontario for over twenty years. After years of sediment and debris buildup, surface clogging reduces the infiltration of stormwater and inhibits the hydraulic and environmental functions of the pavement. Removal of surface material has been shown to restore infiltration but the majority of studies have been limited to small scale testing.

This chapter presents the results and experiences of the first testing of regenerative air and vacuum sweeping trucks on permeable pavements in Ontario, which was conducted in 2011. A regenerative air truck was tested on two parking lots with well used permeable interlocking concrete pavers and pervious concrete, while a vacuum sweeping truck was demonstrated on a third parking lot with permeable interlocking pavers.

Both systems proved to provide partial rehabilitation of the permeable pavements. Post treatment surface infiltration rates on all three parking lots displayed large spatial variability, showing that micro-conditions throughout the pavement have a confounding influence on the overall effectiveness of maintenance. The impact of maintenance may be improved by establishing regular cleaning intervals and developing instructional guidelines for pavement owners and equipment operators.

Drake, J. and A. Bradford. 2013. "Assessing the Potential For Rehabilitation of Surface Permeability Using Regenerative Air and Vacuum Sweeping Trucks." Journal of Water Management Modeling R246-16. doi: 10.14796/JWMM.R246-16. (C) CHI 2013 www.chijournal.org ISSN: 2292-6062 (Formerly in Pragmatic Modeling of Urban Water Systems. ISBN: 978-0-9808853-8-5) 


\subsection{Introduction}

Despite over 20 y research and demonstration, permeable pavement (PP) systems do not receive widespread use throughout many parts of Canada. A commonly cited concern regarding this technology is the belief that pavements will clog rapidly, resulting in loss of infiltration and stormwater management capacity within a relatively short time period. PPs remove pollutants, such as suspended sediments and associated heavy metals and nutrients, from infiltrating stormwater, through the processes of filtration and sedimentation. These removal mechanisms capture and store particulate forms of pollutants inside the voids of the pavement and aggregate layers. Over time, accumulation of materials within the PP system can decrease surface permeability and limit the ability of stormwater to infiltrate (Figure 16.1). In cold climates, the rate of surface clogging is anticipated to be rapid if PPs are exposed to winter road sanding and salting practices. Studies have shown that the removal of accumulated surface material can restore the hydrologic functionality of a PP system (Colandini et al., 1995; James and Gerrits, 2003) but long term clogging processes are still poorly understood. Moreover, practical maintenance techniques have not been extensively tested.
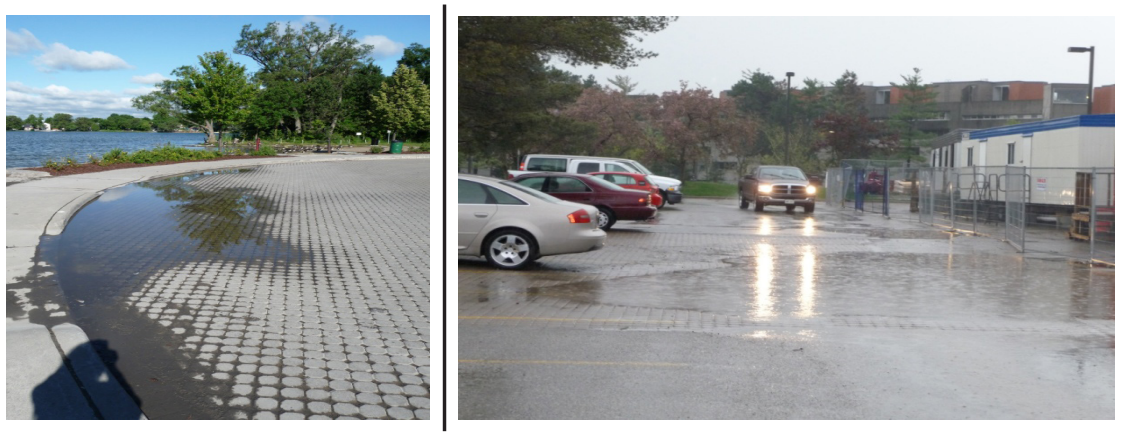

Figure 16.1 Two examples of PPs which have lost their capacity to infiltrate water.

In order to promote the use of PP systems as viable stormwater management systems it is necessary to demonstrate and evaluate the effectiveness of realistic maintenance equipment and methods. Research is currently under way at the University of Guelph to evaluate the long term hydrologic performance of PP systems and to assess the impact of different maintenance techniques on surface permeability. In this chapter the results and experiences of the first testing of regenerative air and vacuum sweeping trucks on PPs in Ontario, conducted in 2011, are presented. 


\subsection{Background Review}

\subsubsection{Clogging Processes}

Clogging, the loss of surface permeability, in PP systems has been documented by numerous researchers in both field (Bean et al., 2007; Henderson and Tighe, 2011) and laboratory based studies (Illgen et al., 2007; Pezzaniti et al., 2009; Haselbach, 2010; Tan et al., 2003). Clogging materials are deposited onto the surface of a PP from vehicular traffic, vegetative litter, atmospheric deposition and regular maintenance activities. Wearing of pavement breaks down the parent material into finer sized particles which can migrate further down into the pavement matrix and underlying aggregate. During a rain or melt event these pollutants mix with stormwater and infiltrate into the PP where they become trapped inside pavement and aggregate voids. Day-today traffic loads compact the fine material creating impervious crusts or seals at the pavement surface. Significant accumulation of clogging material decreases the interconnected void spaces within the PP capable of conveying water, ultimately leading to a loss of permeability (Figure 16.2). The rate of clogging at PP installations is highly variable; in some cases PPs perform well even after many years of use (e.g. Brattebo and Booth, 2003), whereas in other cases rapid permeability losses are observed after only one or two years (e.g. Abbott et al., 2003). Observations of pavement performance have linked rapid permeability losses with several in situ characteristics including winter sanding and snow storage (Boving et al., 2008), high traffic loads (James and Gerrits, 2003; Brattebo and Booth, 2003; Boving et al., 2008), and geotextiles (Boving et al., 2008; Yong et al., 2008; Brown et al., 2009). The clogging process is also influenced by a pavement's physical properties such as pavement type, effective porosity, pore size distribution and tortuosity (Sansalone et al., 2008).
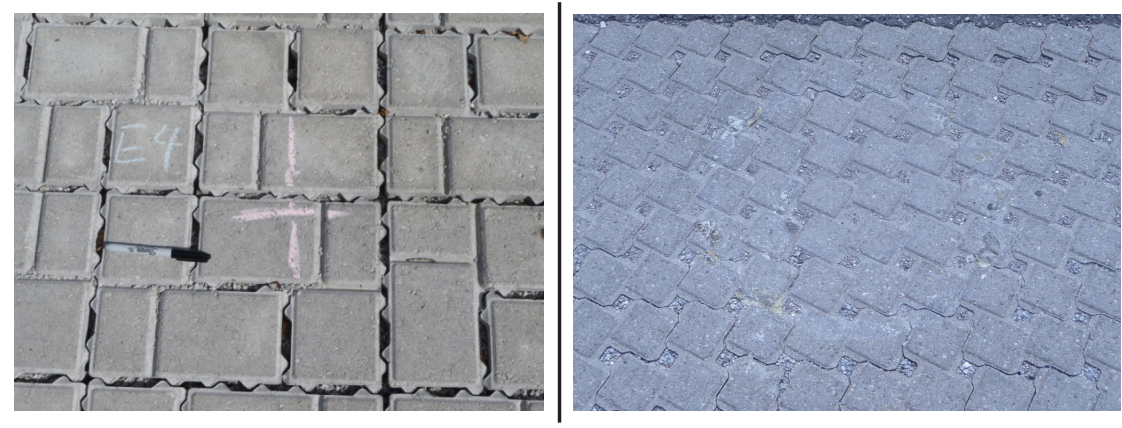

Figure 16.2 New PP installed 2009 (left) and old PP installed 2004 (right). 


\subsubsection{Removal and Rehabilitation Practices}

Removal of surface material has been shown to provide partial or full rehabilitation of surface permeability (Kresin et al., 1997; James and Gerrits, 2003). Baladès et al. (1995) are among the earliest researchers to test practical cleaning treatments on PPs. Their study noted that as clogging becomes more pervasive, more intensive cleaning treatments are required, and they recommended suction for preventative maintenance and pressure washing for rehabilitative maintenance. In recent years researchers have tested a variety of maintenance techniques on PPs:

Henderson and Tighe (2011) tested surface treatments on multiple pervious concrete (PC) parking lots in 2009 and recommended the practice of washing surfaces with a large diameter hose to renew permeability;

- Henderson and Tighe (2011) reported that other surface treatments, such as sweeping with a push broom, vacuum sweeping with a shop vac, and power washing, did not provide significant improvements to pavement permeability; rejuvenation practices of PC cores conducted by Chopra et al. (2010a) recommended pressure washing over vacuum sweeping;

- Chopra et al. (2010b) conducted field tests with an Elgin Whirlwind MV truck on five types of PPs - including FlexiPave, PC, porous asphalt - and two types of permeable interlocking concrete pavers (PICP), which had been artificially clogged: high groundwater levels complicated the study and influenced results but observations still showed that vacuum sweeping could restore permeability; and

- Shirke and Shuler (2010) investigated the effectiveness of reverse flushing on PC cores: the study had promising results but did not discuss how such a technique could be practically implemented.

Understanding and evaluating the effects of maintenance remains one of the most important and pressing topics for PP research. Standardized maintenance practices have not yet been developed, which has likely contributed to the fact that PPs in use throughout Canada are not maintained to protect their hydrologic functionality. Improper maintenance leads to a higher incidence of pre-mature failure because clogging materials are not removed in a timely and regular manner, allowing them to become entrenched within the pavement. Loss of hydrologic functionality, induced by a lack of maintenance, propagates the public perception that PP systems have a short effective life and are erratic materials which do not provide reliable infiltration. Since operators 
are often unaware of the maintenance requirements of their PPs, performance failures, which result from excessive surface clogging, are often interpreted as inherent inadequacies of permeable products instead of the failure being associated with improper maintenance and use. Ultimately, improper maintenance and any subsequent failures create reluctance towards the adoption of PP systems as a stormwater management technique and even skepticism towards low impact development (LID) practices as a whole.

\subsection{Methodology}

The ability of commercial street cleaning trucks to restore surface permeability was tested on three mature, active, PP parking lots, during the summer of 2011. In many areas, suction based street cleaning trucks, such as regenerative air and vacuum sweeping trucks, are replacing traditional mechanical sweepers because they produce less dust and air pollution. Consequently, suction based street cleaners are becoming increasingly accessible for municipalities and private property owners. In order to encourage regular maintenance of surface permeability in PPs, maintenance practices which are cost effective and simple to implement are required. Suction based street cleaning trucks may be one alternative which could be recommended to owners and operators of PP parking lots.

\subsubsection{Site Description}

Site 1 is a commuter drop off and pick up waiting area located at the East Gwillimbury GO Transit station, north of Toronto. The lot, built in 2004, is composed of drive-thru waiting lanes and is constructed using Unilock EcoStone. The PP system is sloped, underdrained and includes base layers of Granular A (150 mm deep) and Granular B (450 mm deep). The parking lot is salted during the winter and is swept annually with a mechanical sweeper.

Site 2 is a cul-de-sac and visitor parking lot located at Earth Rangers in Woodbridge, just north-west of Toronto. The lot, built in 2004, is constructed using Unilock Eco-Stone and receives runon stormwater from impervious paved areas. Exact underlying drainage and base aggregate specifications are not known but it is suspected that base layers include Granular A aggregate. The lot has been sanded during past winters and is swept annually with a mechanical sweeper.

Site 3 is an Ontario Ministry of Transportation (MTO) commuter parking lot located at Hwy 401 and Guelph Line, west of Toronto. The lot, built in 2007, is constructed using PC. Sections of the pavement have experienced 
significant raveling and some areas have been subjected to winter sanding and salting. The parking lot is swept annually with a mechanical sweeper.

\subsubsection{Test Setup}

At all three parking lots, surface permeability was evaluated using the methods for a single ring infiltration test described in ASTM C1701 (ASTM, 2009). Surface infiltration rates were measured before and after surface treatment with the sweeper truck. A few modifications to the ASTM method were implemented during the tests. First of all, modeling clay was used in place of plumbers' putty as the sealant material because the clay performed better under warm conditions $\left(>25^{\circ} \mathrm{C}\right)$. A second modification included an assigned time limit for the pre-wetting test and full test. During pre-wetting and full test infiltration measurements, water was allotted $30 \mathrm{~min}$ and $90 \mathrm{~min}$ to infiltrate, respectively. If water did not completely infiltrate within this time limit the test was recorded as a failed test. Infiltration rates for failed tests are estimated to be $\leq 50 \mathrm{~mm} / \mathrm{h}$. The Interlocking Concrete Pavement Institute recommends cleaning PPs when surface infiltration rates fall below $250 \mathrm{~mm} / \mathrm{h}$ and thus the benchmark of $50 \mathrm{~mm} / \mathrm{h}$ used in this study is well below current hydrologic performance standards.

Sites 1 and 3 were maintained using a regenerative air Tymco-DST 6 truck operating at low speeds $(1 \mathrm{~km} / \mathrm{h}$ to $3 \mathrm{~km} / \mathrm{h}$ ) and maximum power (2 000 $\mathrm{rpm})$. Site 2 was maintained using an Elgin Whirlwind vacuum truck operating at low speeds $(1 \mathrm{~km} / \mathrm{h}$ to $3 \mathrm{~km} / \mathrm{h}$ ) and maximum power (2 $500 \mathrm{rpm})$. Regenerative air trucks have an air recycling system which creates a dustless effect during operation. A wide pickup head has a blower and a vacuum nozzle on opposite sides of the truck. This creates a pressurized system which captures dust and debris along the pavement surface. Vacuum sweeping trucks operate as true vacuums using suction from a vacuum nozzle along one side of the truck to remove dust and debris. During the experiments, truck operators were encouraged to operate their vehicles to maximize the effectiveness of the maintenance. This resulted in differences in approach. Operators at site 2 elected to pre-wet the pavement surface while operators at site 1 and site 3 ran the truck over dry pavement. Tests at site 1 were also affected by a large rain event $24 \mathrm{~h}$ before the maintenance experiment. During the tests the pavement was dry but sediments within the joints were still moist. It is unclear if the rain event impacted the effectiveness of the maintenance. Following the maintenance at sites 1 and 3, new high performance bedding was swept into joints to replace the material that had been removed. During each test, debris samples were collected from the maintenance truck hopper. Samples were sieved in order to analyze the gradation of materials collected by the trucks. 


\subsection{Results}

\subsubsection{Infiltration}

Pre-treatment infiltration measurements revealed that surface permeability had decreased to unacceptably low levels at all three parking lots. At the two PICP lots ponded water was observed in low lying areas after small and moderate rainfall events. Less than $15 \%$ of the pre-treatment measurements had surface infiltration rates $>50 \mathrm{~mm} / \mathrm{h}$. Passing tests were anomalies and high infiltration rates could be attributed to the presence of an isolated opening inside the infiltration ring (Figure 16.3).
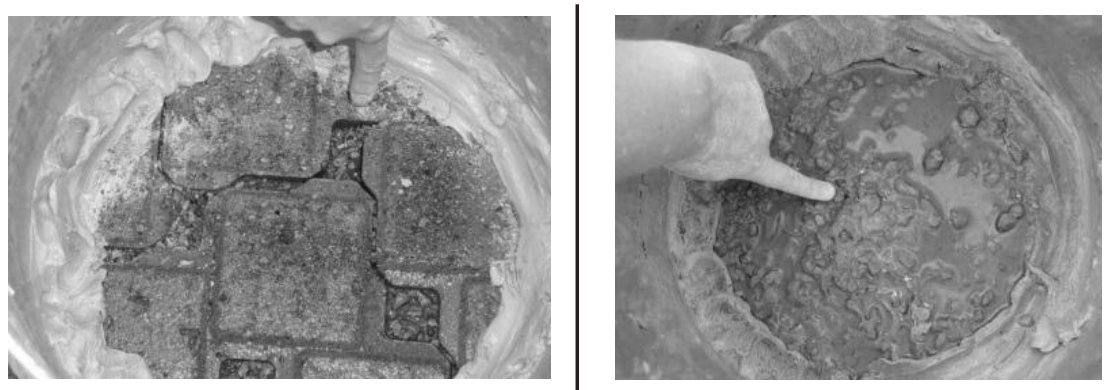

Figure 16.3 Examples of voids contributing to high pre-treatment surface infiltration rates: PICP (left), PC (right).

Table 16.1 summarizes the number of infiltration measurements $>50 \mathrm{~mm} / \mathrm{h}$ and $>250 \mathrm{~mm} / \mathrm{h}$ before and after maintenance. At all three locations after maintenance, at least $50 \%$ of measurements showed surface infiltration rates $>50 \mathrm{~m} / \mathrm{h}$.

Table 16.1 Passing infiltration tests.

\begin{tabular}{ccccc}
\hline Site & Total tests & $\begin{array}{c}\text { Pre-Maintenance } \\
(\mathrm{I}>50 \mathrm{~mm} / \mathrm{h})\end{array}$ & $\begin{array}{c}\text { Post-Maintenance } \\
(\mathrm{I}>50 \mathrm{~mm} / \mathrm{h})\end{array}$ & $\begin{array}{c}\text { Post-Maintenance } \\
(\mathrm{I}>250 \mathrm{~mm} / \mathrm{h})\end{array}$ \\
\hline 1 & 42 & 6 & 26 & 12 \\
2 & 20 & 3 & 13 & 10 \\
3 & 35 & 4 & 16 & 9 \\
\hline
\end{tabular}

Statistics for passing tests ( $\mathrm{I}>50 \mathrm{~mm} / \mathrm{h}$ ) following maintenance are presented in Table 16.2. Passing post-maintenance infiltration rates and associated pre-maintenance rates are reported in Table 16.3. Overall, following maintenance, infiltration rates were shown to be higher than pre-treatment rates but the magnitude of improvement was highly variable. Prior to maintenance mean infiltration rates were less than $50 \mathrm{~mm} / \mathrm{h}$ at all three sites. Following 
maintenance, the lower $95 \%$ confidence interval of the mean measured infiltration rate was $>50 \mathrm{~mm} / \mathrm{h}$ at each site, indicating that the maintenance significantly improved infiltration performance. Maximum recorded rates at sites 1 , 2 and 3 were $2220 \mathrm{~mm} / \mathrm{h}, 3625 \mathrm{~mm} / \mathrm{h}$ and $1366 \mathrm{~mm} / \mathrm{h}$, respectively. Results from site 2 are notably different compared to the results from sites 1 and 3 . In particular, site 2 displayed much larger mean and median infiltration rates. Regardless, infiltration measurements from sites 1,2 and 3 displayed nearly identical variability; the coefficient of variation ranged between 0.9 and 1.1 and a skewness of 1.4 to 1.5 was observed.

Table 16.2 Post maintenance statistics for infiltration tests (I > 50mm/h).

\begin{tabular}{ccccccc}
\hline Site & Mean $(\mathrm{mm} / \mathrm{h})$ & $\begin{array}{c}\text { Median } \\
(\mathrm{mm} / \mathrm{h})\end{array}$ & $\begin{array}{c}\text { SD } \\
(\mathrm{mm} / \mathrm{h})\end{array}$ & Skew & $\begin{array}{c}\text { Coeff. of } \\
\text { Var. }\end{array}$ & $\begin{array}{c}95 \% \text { CI for Mean } \\
(\mathrm{mm} / \mathrm{h})\end{array}$ \\
\hline 1 & 515 & 205 & 586 & 1.4 & 1.1 & $284-746$ \\
2 & 1047 & 529 & 1106 & 1.4 & 1.1 & $424-1670$ \\
3 & 430 & 307 & 404 & 1.5 & 0.9 & $220-640$ \\
\hline
\end{tabular}

Table 16.3 Measured infiltration rates $(\mathrm{mm} / \mathrm{h})$.

\begin{tabular}{ccccccc}
\hline \multirow{2}{*}{ Test } & \multicolumn{2}{c}{ Site 1 } & \multicolumn{2}{c}{ Site 2 } & \multicolumn{2}{c}{ Site 3 } \\
\cline { 2 - 7 } & Pre & Post & Pre & Post & Pre & Post \\
\hline 1 & $<50$ & 68 & $<50$ & 78 & $<50$ & 301 \\
2 & $<50$ & 52 & $<50$ & 78 & 112 & 708 \\
3 & $<50$ & 35 & $<50$ & 529 & $<50$ & 59 \\
4 & $<50$ & 1724 & $<50$ & 1544 & $<50$ & 496 \\
5 & 109 & 457 & $<50$ & 1200 & $<50$ & 150 \\
6 & $<50$ & 83 & $<50$ & 2819 & $<50$ & 540 \\
7 & $<50$ & 59 & 49 & 251 & $<50$ & 588 \\
8 & $<50$ & 793 & $<50$ & 250 & $<50$ & 90 \\
9 & $<50$ & 1278 & $<50$ & 1518 & 38 & 158 \\
10 & $<50$ & 577 & 93 & $<50$ & $<50$ & 334 \\
11 & $<50$ & 756 & 211 & 3625 & $<50$ & 47 \\
12 & $<50$ & 125 & $<50$ & 1003 & $<50$ & 232 \\
13 & $<50$ & 209 & $<50$ & 246 & 350 & 1366 \\
14 & $<50$ & 201 & $<50$ & 471 & $<50$ & 313 \\
15 & $<50$ & 106 & & & 250 & 1306 \\
16 & $<50$ & 62 & & & $<50$ & 196 \\
17 & 64 & 33 & & & & \\
18 & $<50$ & 1139 & & & & \\
19 & $<50$ & 875 & & & & \\
20 & 697 & 1139 & & & & \\
21 & $<50$ & 2220 & & & & \\
22 & $<50$ & 95 & & & & \\
23 & $<50$ & 36 & & & & \\
24 & 782 & 719 & & & & \\
25 & 190 & 398 & & & & \\
26 & 131 & 140 & & & & \\
\hline & & & & & & \\
\hline
\end{tabular}




\subsubsection{Collected Surface Material}

The gradations of surface materials collected inside the trucks' hoppers is presented in Table 16.4. The regenerative air and vacuum trucks have different collection systems which would have influenced the gradation results. The regenerative air truck had a secondary collection compartment where the majority of fine material is captured. Results presented here only include coarse material collecting in the main hopper of the regenerative air truck. Collected material from the vacuum truck hopper was less accessible and grab samples could not be collected until a large amount of material had accumulated inside the hopper. The material collected inside the truck hoppers was very coarse and contained only small amounts of fine material. Specifically, a very small percentage of material, $<5 \%$, passed through the $\# 200$ sieve.

Table 16.4 Average gradation of hopper samples.

\begin{tabular}{ccccc}
\hline \multirow{2}{*}{ Sieve \# } & \multirow{2}{*}{ Opening $(\mathrm{mm})$} & \multicolumn{3}{c}{ Percent Passing $(\%)$} \\
\cline { 3 - 5 } & & Site 1 & Site 2 & Site 3 \\
\hline 4 & 4.75 & 84.8 & 80.0 & 81.7 \\
10 & 2 & 58.4 & 38.6 & 62.0 \\
20 & 0.85 & 36.0 & 22.8 & 35.9 \\
40 & 0.425 & 16.5 & 12.2 & 19.0 \\
60 & 0.355 & 7.2 & 7.0 & 12.0 \\
100 & 0.15 & 3.4 & 4.6 & 7.8 \\
140 & 0.106 & 2.4 & 3.9 & 6.1 \\
200 & 0.075 & 1.6 & 3.3 & 4.7 \\
\hline
\end{tabular}

\subsubsection{General Observations}

In addition to the infiltration tests and hopper samples detailed observational notes were recorded during the maintenance testing. The following are the most notable observations recorded during each experiment.

Site 1

Severely clogged areas such as parking lot entrance and low-lying curbs showed no improvement;

material inside paver joints was extremely compacted and formed a strong seal with the pavers;

passes with the regenerative air truck sometimes revealed that compacted and entrenched fines were located below superficial coarse aggregates;

- surface suction alone would not remove joint material if the compacted fines formed a complete seal with the pavers; 
once the seal was broken joint aggregate and fine material was removed easily by the maintenance truck;

pre-treatment of pavers to loosen or disturb compacted joint material may increase the effectiveness of maintenance; and joint material was only removed from surfaces passing below the vacuum nozzle.

Site 2

Improvements to surface permeability were larger in areas of lower traffic loadings;

material inside joints was less compacted and entrenched compared to site 1;

material inside joints in low lying area subjected to frequent ponding was notably finer compared to areas where ponding did not occur regularly;

- clogging material inside joints in low lying areas extended down the entire depth of pavers ( 3 in., $7.62 \mathrm{~mm}$ ); and after repeated passes the vacuum truck was successful in removing joint material in low lying areas.

Site 3

The parking lot did not contain any low lying areas and ponding was not observed at this location; as one of the earliest installations of PC in Ontario, the pavement is suspected to have lower permeability as a result of inexperience with mix design and placement techniques;

- clogging materials seemed to be more evenly distributed and appeared to be less compacted and entrenched than site 1 and site 2;

- the effects of winter sanding on surface permeability were reversible with multiple passes of the regenerative air truck; and removal of surface material was observed along the entire width of the pick-up head but was more extensive for areas directly below the vacuum nozzle.

\subsection{Discussion}

The pre-maintenance measurements indicated that the un-maintained PPs were not meeting hydrologic performance standards (I $>250 \mathrm{~mm} / \mathrm{h}$ ). At site 1 this finding was especially surprising because although surface ponding was observed in low lying areas, it occurred in a relatively small section of 
the parking lot. At first glance joints appeared to be open in many areas of site 1 . However, during the pre-maintenance measurements, it was observed that compacted fines were present beneath a shallow layer of loose course aggregate. This highlights the limitation of visual inspections when assessing surface permeability. In the past, isolated maintenance has been recommended for pavement sections experiencing ponding. The experiences at site 1 suggest that the presence of ponded water should be interpreted as a symptom of widespread and pervasive clogging throughout the PP. Ponding over small sections of PP indicate the presence of reduced surface permeability over large surface areas.

The low pre-maintenance infiltration rates of the parking lots demonstrated that without specialized maintenance PPs may become clogged even if they are not subjected to winter sanding. Annual mechanical sweeping does not appear to have any benefit on sustaining surface permeability. As all three parking lots were $<10 \mathrm{y}$ old it is clear that maintenance should be implemented at least several years earlier. Consequently, the surface treatments performed as a part of this study more closely resemble rehabilitation practices as opposed to preventative maintenance practices.

The results confirmed that large scale sweeper trucks which utilize surface suction can provide partial restoration of surface permeability for PPs.

Throughout this study it became apparent that the trucks did not provide consistent rehabilitation throughout the parking lot. Following maintenance, some pavement sections displayed dramatic improvements in surface permeability while other sections remained unchanged. Practically, a success rate of $50 \%$, which was observed at all three sites, is disappointing. The near-identical variability in post-maintenance infiltration rates suggests that the spatial effectiveness of maintenance is independent of the equipment used during the experiment. At all three locations it was observed that maintenance was less effective in areas of high traffic loading and in low lying areas which experience regular surface ponding.

The effectiveness of maintenance can likely be improved by implementing clear guidelines for equipment operators. Some practices which may generate more uniform results include:

1. Implementing a minimum number of passes over the pavement with maintenance equipment;

2. Specifying weather conditions which allow for maximum removal rates of surface materials;

3. Developing pre-treatment practices to make compacted material more susceptible to removal;

4. Creating visual inspection procedures; 
5. Performing infiltration tests between rounds of maintenance; and

6. Performing maintenance on regular intervals such as an annual or bi-annual basis.

Additional testing is required to evaluate and compare the suitability of regenerative air and vacuum trucks for preventative maintenance and rehabilitation for PP systems. Since different equipment was used at different locations it is not possible to make direct comparisons between the two technologies. The two parking lots maintained with the regenerative air truck (site 1 and site 3 ) had very similar post-maintenance infiltration rates. Coarse materials collected in the truck hopper, sieve \#4 through sieve \#40, also had nearly identical gradations even though the parking lots consisted of different types of PPs. However, without side-by-side testing it is unclear if these results are a coincidence or a reflection of the performance of the regenerative air truck.

The effectiveness of maintenance will benefit from specialized procedures which address the different clogging processes involved in PICP and PC pavements. Clogging material in modular PPs is concentrated into the open joints in between pavers. The fine sediments become compacted and entrenched inside the joints forming very strong impervious seals or crusts. At both PICP sites a single pass of the sweeper truck could not always remove the joint material if the encrusted surface remained completely intact.

These observations agree with small scale tests conducted at the University of Guelph which have found that pre-treatment, of an abrasive action to dislodge or disturb crusted joints, followed by surface suction, significantly improves surface permeability (Drake, unpublished data). For large scale maintenance this may mean fitting sweeper trucks so that joints are blasted with pressurized water or air followed by suction from the vacuum nozzle.

Alternatively, multiple techniques may be necessary, such as pressure washing followed by vacuum sweeping. The sweeper trucks remove both clogging and bedding material inside the joints and fresh bedding must be installed following maintenance. In this study new high performance bedding was swept back into the joint by hand which is a time consuming and labour intensive practice. Maintenance of PP is more likely to be performed regularly if it is simple and fast; therefore techniques to rapidly replace bedding material need to be developed.

Unlike PICPs clogging material within poured permeable pavements such as PC remain distributed throughout the pavement. If fines are allowed to migrate too far into the pavement matrix it may be impossible to extract the clogging material and surface permeability may be permanently affected. 
Because of this risk shorter intervals between maintenance may be appropriate for poured PPs.

\subsection{Recommendations}

The following are recommendations for future research, based on the experience gained from the maintenance experiments. They are issues which were not examined as a part of this study and include:

assessing the impact of suction based street cleaners as a part of preventative maintenance;

evaluating the differences and benefits of regenerative air and true vacuum sweeper systems for maintaining PPs;

- isolating confounding variables (e.g. pavement age, traffic loadings, sediment and vegetative inputs, antecedent weather) which influence the effectiveness of maintenance, and quantifying their effect on surface permeability; optimizing equipment operations to maximize the impact of maintenance (e.g. pre-wetting, truck speed and broom usage);

- determining the type and frequency of maintenance required to sustain acceptable surface infiltration rates; and examining the different clogging processes and maintenance needs of modular and poured PPs.

\subsection{Conclusion}

The study of the maintenance of PPs using regenerative air and vacuum sweeping trucks presented in this chapter is the first of its kind in Ontario. The purpose of these tests was to explore the suitability and effectiveness of large scale sweeper trucks for restoring and rejuvenating surface permeability.

Pre-treatment infiltration measurements revealed that all three PPs had poor surface permeability and, as a result, tests with the sweeper trucks resembled rehabilitation practices not preventative maintenance. Under these conditions it was shown that regenerative air and vacuum trucks provide partial restoration of surface permeability. Overall, $50 \%$ of the cleaned surfaces displayed improved surface permeability after maintenance.

The results indicate that suction based sweeper trucks are well suited to rehabilitative maintenance. The street cleaning equipment used as a part of this study will undoubtedly be more effective on PPs with less severe clogging and thus it is also recommended for preventative maintenance applications. Future research is needed to optimize maintenance procedures. 


\section{Acknowledgments}

Use and operation of the Elgin Whirlwind vacuum truck was provided by Joe Johnson Equipment, Innisfil, Ontario. Use and operation of the Tymco DST-6 truck was provided by The Equipment Specialists Inc., Hamilton, Ontario. Access to parking lots was provided by GO Transit, Earth Rangers and MTO. Funding for the research was provided by NSERC, the Natural Sciences and Engineering Research Council of Canada. Additional technical services were provided by the Sustainable Technologies Evaluation Program (STEP) through TRCA, the Toronto and Region Conservation Authority.

\section{References}

Abbott, C. and Comino-Mateos, L. (2003). In-situ hydraulic performance of a permeable pavement sustainable urban drainage system. J. Chart. Inst. Water Eng., 17(3), 187190.

ASTM. (2009). ASTM C 1701 Standard Test Method for Infiltration Rate of In Place Pervious Concrete. In Annual Book of ASTM Standards (Vol. 04.02). Conshohocken: American Society for Testng and Materials International.

Balades, J. D., Legret, M., and Madiec, H. (1995) Permeable Pavements: Pollution Management Tools. Water Science and Technology. 32(1): 49-56

Bean, E., Hunt, W. and Bidelspach, D. (2007b). Field survey of permeable pavement surface infiltration rates. J. Irrig. Drain. Eng., 133(3), 249-255.

Boving, T., Stolt, M., Augenstern, J. and Brosnan, B. (2008). Potential for localized groundwater contamination in a porous pavement parking lot setting in Rhode Island. Environ. Geol., 55(3), 571-582.

Brattebo, B., and Booth, D. (2003). Long-term stormwater quantity and quality performance of permeable pavement systems. Water Res., 37(18), 4369-4376.

Brown, C., Chu, A., van Duin, B. and Valeo, C. (2009). Characteristics of Sediment Removal in Two Types of Permeable Pavement. Water Qual. Res. J. Can., 44(1), 59-70.

Chopra, M., Kakuturu, S., Ballock, C., Spence, J. and Wanielista, M. (2010a). Effect of rejuvenation methods on the infiltration rates of pervious concrete pavements. J. Hydrol. Eng., 15(6), 426-433.

Chopra, M., Stuart, E. and Wanielista, M. (2010b). Pervious pavement systems in Florida research results. Low Impact Development 20010: Redifining Water in the City (pp. 193-206). San Fransisco: ASCE.

Colandini, V., Legret, M., Brosseaud, Y. and Baladès, J.-D. (1995). Metallic pollution in clogging materials of urban porous pavements. Water Sci. Technol., 32(1), 57-62.

Haselbach, L. (2010). Potential for clay clogging of pervious concrete under extreme conditions. J. Hydrol. Eng., 15(1), 67-69.

Henderson, V. and Tighe, S. (2011). Evaluation of pervious concrete pavement permeability renewal maintenance methods at field sites in Canada. Can. J. Civ. Eng., 38(12), 1404-1413. 
Illgen, M., Harting, K., Schmitt, T. and Welker, A. (2007). Runoff and infiltration characteristics of pavement structures-review of an extensive monitoring program. Water Sci. Technol., 55(10), 133-140.

James, W. and C. Gerrits. 2003. "Maintenance of Infiltration in Modular Interlocking Concrete Pavers with External Drainage Cells." Journal of Water Management Modeling R215-22. doi: 10.14796/JWMM.R215-22.

Kresin, C., W. James and D. Elrick. 1997. "Observations of Infiltration Through Clogged Porous Concrete Block Pavers." Journal of Water Management Modeling R195-10. doi: 10.14796/JWMM.R195-10.

Pezzaniti, D., Beecham, S. and Kandasamy, J. (2009). Influence of clogging on the effective life of permeable pavements. Water Manage., 62(WM3), 211-220.

Sansalone, J., Kuang, X. and Ranieri, V. (2008). Permeable pavement as a hydraulic and filtration interface for urban drainage. J. Irrig. Drain. Eng., 134(5), 666-674.

Shirke, N. and Shuler, S. (2009). Cleaning porous pavements using a reverse flush process. J. Transp. Eng., 135(11), 832-838.

Tan, S., Fwa, T. and Han, C. (2003). Clogging evaluation of permeable bases. J. Transp. Eng, 129(3), 309-315.

Yong, C., Deletic, A., Fletcher, T. and Grace, M. (2008). The clogging behaviour and tretment efficiency of a range of porous pavements. 11th International Conference on Urban Drainage, (pp. 1-10). Edinburgh. 
